\title{
A Comparative Analysis on Cohesive Markers in Essay Composition of First Language and Second Language: Direct Writing Versus Translation
}

\author{
Noor Shahariah Saleh ${ }^{1} \mathbf{8}(D) \square$ Siti Fatimah Murtaza ${ }^{2}$ (D) and Nurshila Umar Baki ${ }^{3}$ (D) \\ ${ }^{7}$ Academy of Language Studies, Universiti Teknologi MARA Cawangan Negeri Sembilan Kampus Seremban, Persiaran Seremban \\ Tiga/1, 70300 Seremban, Negeri Sembilan, Malaysia \\ ${ }^{2}$ Centre for Language Studies, Universiti Tun Hussein Onn Malaysia, 86400 Parit Raja, Batu Pahat, Johor, Malaysia \\ ${ }^{3}$ SMA Shamsuddiniah, Parit Medan, Kundang Ulu, 84710 Tangkak, Johor \\ $\square$ Corresponding Author: Noor Shahariah Saleh, E-mail: noorshahariah@uitm.edu.my
}

\section{ARTICLE INFORMATION}

Received: August 08, 2021

Accepted: September 14, 2021

Volume: 1

Issue: 2

DOI: 10.32996/ijls.2021.1.2.1

\section{KEYWORDS}

Cohesive markers, translated writing, direct writing, L1 transfer and L2 writing

\section{ABSTRACT}

Studies have revealed that first language has significant impacts on learners' second language development. Utilizing L1 in the writing processes such as translation method and direct writing is a conventional strategy used by low proficiency level $L 2$ learners. However, there is a lack of studies that determine the quality of writing influenced by L1 transfer. This study aims to provide a comparative analysis on the use of cohesive markers as a result of the use of Malay in English written text via translation and direct composition. The writing quality in terms of content, organisation and writing style of a group of students with low, intermediate and advanced proficiency levels from a secondary school in the district of Tangkak, Johor was scrutinised. Data were collected via two different topics of writing tasks using direct composition and translation writing process. The first topic involved English direct composition while the second topic employed direct Malay composition which was then translated into English. The results of the study indicated that English essays of direct writing showed less variety of cohesive markers as compared to Malay essays due to the lack of L2 writing skills. The learners apparently generated more ideas in their native language as well as utilized their L1 cohesive markers into L2 composition via the translation writing process. Nevertheless, the similarities and differences of cohesive markers in Malay and English help teachers to understand learners' organisation of Malay and English essays.

\section{Introduction}

Early studies mainly indicated the negative influence of $L 1$ on $L 2$ development. Based on the notion that acquisition is better than learning, the main principle is that L2 teachers and learners should use only L2 in the classroom as the use of L1 could be detrimental to the process. Theories like Krashen's monitor theory are the main foundation to this principle. In the 1980s, there was a shift of interest from product to process orientation. Research studies have begun to acknowledge the more positive role of L1 on L2 development. For instance, Cummins (1989), through his common underlying proficiency (CUP) model of bilingualism, highlighted the importance of L1 in developing $\mathrm{L} 2$.

Research has identified L1 as a salient writing strategy utilized by L2 learners. It is considered as a compensatory strategy to overcome writing difficulties faced by L2 learners especially by the lower proficiency group (Lifang, 2008; Stapa \& Majid, 2012). In addition, several studies have analysed the effects of using different writing processes such as direct writing and translation method (Kobayashi \& Rinnert, 1992; Ahmed Ismail \& Omer Alsheikh, 2012; Petchprasert, 2013). These studies have discovered that the lower proficiency learners of L2 gained more benefits from composing in L1 and then translating into L2 writing. This highlights the importance of using L1 composing strategies for lower L2 proficiency writers.

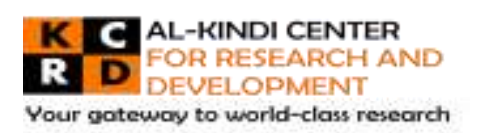

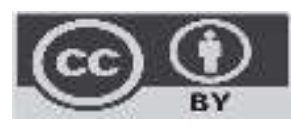

Published by Al-Kindi Center for Research and Development. Copyright (c) the author(s). This open access article is distributed under a Creative Commons Attribution (CC-BY) 4.0 license 
In determining the quality of writing, it is essential to distinguish the criteria. Studies have indicated that the relationship between coherence and cohesion is actually the basis to ascertain the quality of writing as well as its process (Johnson, 1992). Based on Halliday and Hasan's (1976) study, cohesive devices are recognised as important linguistic elements which indicate the coherence of well-written essays.

Besides, there is a lack of literature on the analysis of cohesion used in L1/L2 Malay upper secondary school students' writing and their quality of writing. Most studies used university students as research participants. Only a few studies were conducted on ESL writings of primary or secondary school students that involve different levels of language proficiency. Thus, this study seeks to analyse the frequency rates of cohesive markers used in Malay and English written texts of three levels of proficiency of ESL upper secondary school students as it is an indicator of the quality of their writing.

\section{Literature Review}

\subsection{L1 Transfer}

First language (L1) transfer in acquiring the second language (L2) has been discussed for centuries. It is argued that L1 transfer can aid in improving L2 skills or it can merely be a problem to learners in acquiring new knowledge in the second language. According to Selinker (1983), when the knowledge of $L 1$ involves in learning and it helps in the attainment of $L 2$, the process is considered a positive transfer. Meanwhile, it is considered a negative transfer when the process is obstructed by L1 knowledge and it results in negative effects to the learners. The system where it is placed in between learners' L1 and L2 language is called interlanguage (Selinker, 1983). Therefore, it is clear that language transfer can be either a trigger or interference to learners in learning a second language.

Based on Contrastive Analysis Hypothesis by Lado (1957), L1 patterns have a great impact on learners' skills of production and reception in L2. The way learners perceive the easiness or complexity of $L 2$ is related to the resemblances and discrepancies between L1 and L2. However, Gass (2000) states that the learners play a crucial role in deciding to transfer or not to transfer from $\mathrm{L} 1$ to $\mathrm{L} 2$ as the transfer is viewed more as a routine. Considering the learners as the main concern and vigorous contributors in learning, L1 transfer brings significance to the process. Here, language is explained by Karim and Nassaji (2013) as a learnergenerated process that has the same function as other processes engaged in acquiring a language.

Transfer occurs in $\mathrm{L} 2$ writing to balance the absence of knowledge that learners face. When learners have intricate ideas or thoughts to be conveyed and they have limited knowledge of the language to be accessed, they turn to transfer. This is stated by Karim and Nassaji (2013) that L1 is dependent in order to cater to the need to convey their ideas in L2 during the writing process. While learners transfer from L1 to $L 2$, there is a probability that errors happen. It is because learners make generalisations of the knowledge that they acquire in $L 2$. It is also due to the different features of $L 1$ that learners tended to transfer to $L 2$ that learners are not aware of the difference (Eckman, 1977).

\subsection{Cohesion}

This study applied the English and Malay language frameworks for cohesion. The cohesion that was observed in this study only covers the type of grammatical cohesion, namely reference, conjunction, ellipsis and substitute. As for English cohesion, it was based on Halliday and Hasan's (1976) work while the Malay cohesion considers several references by Asmah (1986), Nik Safiah et al. (1993), as well as Liaw and Abdullah (1994) for reference (kata rujukan) and conjunction (kata hubung) and Ali (1996) for ellipsis (pengguguran) and substitution (penggantian).

Reference relates an element in a text with another element that the reference is defined in the occurrence (Halliday and Hasan, 1976). According to Witte and Faigley (1981), there are three types of reference in English cohesion which are pronominals, demonstratives or definite articles and comparatives. As for the Malay language, Asmah (1986), Nik Safiah Karim et al. (1993), as well as Liaw and Abdullah (1994) mention that the function of reference (kata rujukan) does not differ from the ones in English. The Malay cohesion too has three parts namely pronominal (rujukan diri), demonstratives (rujukan petunjuk) and comparatives (rujukan perbandingan).

Based on Halliday and Hasan (1976), conjunctive cohesion can be classified into five types which are additive, adversative, continuative, temporal and causal. Conjunction serves the function to connect ideas in text and provides cohesive relationships in the sentence (Witte \& Faigley, 1981). Kata hubung (conjunction) in the Malay language is used to explain the relationship or connection between related words, words with the phrase, phrase with phrase, and sentence with a sentence (Liaw \& Abdullah, 1994).

Substitute occurs in a text when a replacement is made to a word or phrase that brings new knowledge (Tangkiengsirisin, 2010). In English, a substitute is used more in spoken rather than in written text. Substitution in Malay cohesive is about replacing or substituting a word or phrase that has been mentioned or used by a regular single word (Ali, 1996). It can be applied in either 
writing or speaking. Meanwhile, ellipsis happens when a word, phrase or clause in a sentence or text is removed (Witte \& Faigley, 1981). According to Ali (1996), the cohesion of ellipsis (pengguguran) is applied in both written and spoken language of Malay. It is employed in a sentence by deleting the redundant or repeated phrase or word.

\subsection{Process of Writing}

Writing is a skill that is challenging and it includes a process that is complex that even the first language learners find it hard to acquire (Rassouli \& Abbasvandi, 2013). Abbas et al. (2020) explain that acquiring the quality writing ability and robust comprehension in English is generally distinguished through the use of lexical and grammatical elements like syntactic structure, grammatical and lexical cohesive devices etc. thus making them a major source of difficulty for EFL/ESL writers. Silva (1993) agrees that there is a possibility for the L1 writing skills to be transferred to L2. This puts into consideration the learner's proficiency level that exceeds a particular point when they are capable of relocating those abilities. In consequence, the performance in L2 writing is related to the variability of learners. For instance, the higher learners' proficiency in language resulted in better quality of writing (Myles, 2002). However, Myles (2002) explains that the issue of applying L1 theories and instructional model L2 instruction is the writing process in L2 which also requires cognitive related tasks in the second language when learners produce a significant text.

There are many studies looking at the transfer of $L 1$ to $L 2$ in writing. Stapa and Majid (2006) studied the use of $L 1$ which was Bahasa Malaysia in English writing. It was found that the use of L1 managed to produce a higher value of ideas among students not just in groups but also individually. This led to the greater quality of essays that covered the language, content, vocabulary and body structure. It was suggested by Stapa and Majid (2006) that low proficiency students should apply the L1 in L2 writing to activate the learners' knowledge background.

Another study that looked into the transfer of $L 1$ into $L 2$ writing was conducted by Van Weijen et al. (2009). Investigating 20 Dutch native speakers who graduated from pre-university education, the researchers intended to view to what degree L1 is being implemented in performing cognitive activities throughout $L 2$ writing. This study also scrutinised the effect of L1 in text quality as well as how far collective writing proficiency and L2 proficiency influence arête of text. Van Weijen et al. (2009) managed to underscore that L1 was applied in the writing minimally while writing in L2. It was foreseen that cognitive activities were related to the use of $\mathrm{L} 1$ in writing. This research proved that $\mathrm{L} 2$ proficiency showed no effect on the writing process but directly recounted the quality of $L 2$ text. However, the proficiency of general writing prevailed over the learners' $L 2$ text quality directly and indirectly through the writing process.

Youngran Kim and Hyunsook Yoon (2014) discovered the connection of L1 use in L2 by means of the different proficiency levels, writing genres, and writing tasks. The researchers involved nine Korean-speaking students with elementary, intermediate and advanced proficiency level, to complete argumentative and narrative types of genres which were three for each of them. Besides, the researchers scrutinised the functions of using L1 in L2 writing through the writing task analysis and interviews. The study proceeded to understand how those strategies of L1 use differed with Korean learners' proficiency levels, tasks and genres of writing. The low level of proficiency learners were identified to apply more L1 but all learners use L1 for different degrees. Language proficiency was viewed to have a steady relationship with the kinds of strategies used in L2 writing. The comparable variety of writing strategies implemented in writing allowed dissimilar ways of applying the strategies. It was also suggested that the use of L1 as a trigger to advance L2 writing.

In line with earlier studies (Lifang, 2008; Petchprasert, 2013), the present study employs Kobayashi and Rinnert's (1992). The primary aim of the current study is to present a comparative analysis of frequency rates of cohesive markers used in Malay and English written texts of ESL upper secondary school students. By assigning the translation and direct essay writing to the participants, the L2 students' quality of writing with respect to content, organization and writing style of low, intermediate and advanced ESL students' proficiency levels was examined. This leads the researchers to identify the frequency rates of cohesive markers used in Malay and English written texts. Hence, the research questions of this study are:

1. Is there a significant correlation between the quality of Malay and English writings with respect to content, organization and writing style (low, intermediate and advanced proficiency levels)?

2. What is the frequency of each type of English and Malay cohesion found in English and Malay essays?

\section{Method}

This study was primarily conducted to present a comparative analysis of frequency rates of cohesive markers used in Malay and English written texts of ESL upper secondary school students.

\subsection{Research Design}


A correlational research design serves to predict outcomes as well as to clarify the correlation among variables without any attempt to manipulate the variables (Cresswell, 2014). Thus, this study employed a correlational research design with its primary focus to identify the correlation between the quality of Malay and English writings with respect to content, organization and style via the statistical correlation test. In addition, this study attempts to look into the frequency of types of English and Malay cohesion in participants' essays and its relation to participants' English proficiency levels (low, intermediate and advanced).

\subsection{Research Sample}

A sample of nine Form 4 students in an intact group from a secondary school in the district of Tangkak, Johor was selected. The participants were identified based on purposive sampling with an intention to obtain specific information. Thus, the samples were homogeneous. Participants were 16 years old and of the Malay ethnicity. In order to determine their proficiency level, initially, a group of twenty students sat for a test that utilized Sijil Pelajaran Malaysia (SPM) English 1119 Paper 2. SPM is a standardized public examination in Malaysia or the Malaysian Certificate of Education is set and examined by the Malaysian Examinations Syndicate (Lembaga Peperiksaan Malaysia).

\subsection{Research Instrument}

The primary research instrument implemented in this study is the writing tasks. It was carefully selected to elicit participants' responses. Two narrative topics were selected with regard to students' familiarity with the topics and they are culturally neutral. The first topic was "The person who has inspired me the most" and another topic was "The most impressive place I have visited". These topics were adopted from the SPM past years English 1119 Paper 1.

\subsection{Research Procedure}

The participants started with writing the first composition directly in English (English Direct Writing) and followed by writing the second topic in their mother tongue, Bahasa Malaysia. Based on the Bahasa Malaysia direct writing composition, participants translate their writings into English (translation writing). No usage of the dictionary was allowed during the writing tasks. All writings were done on the same day. Each task was allotted 30 minutes with a 20-minute break in between the task due to time constraints.

\subsection{Data Analysis}

The researchers performed 2 stages of the data analysis process. In the first stage, 27 written essays' writing quality was assessed by two experienced SPM paper raters; a Malay language teacher evaluated 9 Malay written tasks (Malay direct writing) whilst the remaining 18 written tasks (including 9 English direct writing and 9 English translation writing) were assessed by an English language teacher. The assessed written essays were then inter-rated by another two raters. All raters are experienced teachers with more than 15 years of teaching experience and SPM examiners. Each written essay was analytically rated based on 11 subcomponents of writing categories by Kobayashi and Rinnert (1992). This rating scheme is holistically judged on a 10-point scale of content (specifics, developed ideas, overall clarity, interest and thesis), organisation (introduction, logical sequence, conclusion and unity) and style (vocabulary and variety of form). The descriptive statistical analysis tool (SPSS) was employed to determine the correlation between the writing quality of the 27 written essays and participants' English proficiency levels that then tabulated into three distinct tables according to 1) text quality of English direct writing method 2) text quality of English translation method and 3) text quality of Malay language direct method.

The second stage of data analysis required the researchers to adopt Halliday and Hassan (1976)'s English cohesion categories while Malay cohesion categories were obtained from Asmah (1986), Nik Safiah (1993), and Liaw \& Abdullah (1994). The researchers used manual count to identify the frequency of each type of English and Malay cohesion in the essays. The calculated data were presented in three-bar graphs with regard to three different proficiency levels.

\section{Results and Discussion}

\subsection{Stage 1: Proficiency level and the quality of writing}

The 27 essays were scored by four teachers, two for each language respectively. The 27 texts were rated analytically, using Kobayashi and Rinnert (1992) 11 subcomponents of writing and assessed holistically on a 10-point scale based on three main writing categories: Content, Organisation and Style.

To determine the inter-rater reliability, the Pearson product-moment correlation coefficients were used for each pair of raters in direct writing and translation methods.

Table 1: Inter-rater Reliability for Scoring of the Essays 


\begin{tabular}{|l|l|l|l|}
\hline Rater A and Rater B & $\begin{array}{l}\text { English Direct } \\
\text { Method }\end{array}$ & $\begin{array}{l}\text { English Translation } \\
\text { Method }\end{array}$ & $\begin{array}{l}\text { Malay Direct } \\
\text { Method }\end{array}$ \\
\hline Content & 0.96 & 0.86 & 0.85 \\
\hline Organisation & 0.89 & 0.82 & 0.85 \\
\hline Style & 0.96 & 0.92 & 0.83 \\
\hline
\end{tabular}

${ }^{*}$ Correlation is significant at the 0.01 level.

Both raters for English as well as Bahasa Malaysia indicated a strong and positive relationship presented in Table 1. The writing process and proficiency level were discovered to be the two significant factors to affect the quality of writing. Of the two writing modes for English, translations were rated higher than direct compositions (total mean scores: 4.67 for direct composition and 4.98 for translated composition with higher scores for all subcomponents except for style in advance-level group. This pattern was particularly strong with the intermediate-level group that showed significant improvement with the translation scores: $8.4 \%$, $6.6 \%$ and $3.3 \%$ higher for content, organisation and style, respectively.

Table 2: Means of Dependent Measures for the Three Groups

(Content, Organization and Style)

\begin{tabular}{|c|c|c|c|c|c|c|c|c|c|}
\hline \multirow[t]{2}{*}{ Proficiency } & \multicolumn{3}{|c|}{ Means of direct writing mode } & \multicolumn{3}{|c|}{ Means of translated writing mode } & \multicolumn{3}{|c|}{$\begin{array}{l}\text { Means of Malay direct } \\
\text { writing }\end{array}$} \\
\hline & $\mathrm{C}$ & 0 & $\mathrm{~S}$ & $\mathrm{C}$ & $\mathrm{O}$ & $\mathrm{S}$ & C & $\mathrm{O}$ & $\mathrm{S}$ \\
\hline Elementary & 4.17 & 3.50 & 2.83 & 4.17 & 3.83 & 3.33 & 7.17 & 6.17 & 5.17 \\
\hline Intermediate & 4.33 & 3.67 & 4.00 & 5.17 & 4.33 & 4.33 & 6.33 & 5.50 & 4.50 \\
\hline \multirow[t]{2}{*}{ Advance } & 7.17 & 5.83 & 6.50 & 7.33 & 6.33 & 6.00 & 7.50 & 6.17 & 6.00 \\
\hline & \multicolumn{3}{|c|}{ Total means $=$} & \multicolumn{2}{|c|}{ Total means $=$} & 4.98 & \multicolumn{2}{|c|}{ Total means $=$} & 6.06 \\
\hline
\end{tabular}

* $\mathrm{C}=$ content, $\mathrm{O}=$ organisation, $\mathrm{S}=$ style; maximum $=10$, minimum $=1$ for each subcomponent

Nevertheless, there is one exception where direct writing was scored better than translated writing in the advance-level group. Their proficiency level somehow affected their performance as they are able to think and write directly in English. Word by word translation may be an obstacle to their style of writing. Therefore, they rely on their L2 writing strategies.

As what is observed from the findings in Table 2, the lower and intermediate proficiency groups benefited from translation writing mode. This may be due to the fact that fewer cognitive activities such as generating and organizing ideas were required if compared to direct writing mode. They only concentrated on their linguistic activities. This finding is in accordance with the result in studies conducted by Kobayashi and Rinnert (1992) and Lifang (2008) in relation to low and average proficiency levels as well as their L1 transfer.

On the contrary, participants did not use sophisticated vocabulary due to time constraints and different writing procedures in comparison with the study done by Kobayashi and Rinnert (1992). In Kobayashi and Rinnert's (1992) study, participants were given an hour during class to write an essay whereas in the present study, due to time limitation, students were given only thirty minutes to write each essay. All the essays were written within one day. This also indicated participants' lack of L2 vocabulary which also influenced the quality of their writing. Thus, there was a tendency for lower and intermediate level groups to transfer word by word resulting in non-grammatical structures that affect the quality of writing. Even though the length of translated writing compositions increased in length, but not in terms of quality. One example of a sentence by a lower proficiency student in writing the translated composition is as follows.

Pada petang itu, aktiviti pertama kami sekeluarga adalah melawat muzium di Kuching. (Malay direct essay)

For evening activity first we do a go to muzium at Kuching. (English translated essay)

\subsection{Stage 2: Frequency rates of English and Malay cohesion in English and Malay essays}

In order to answer the second research question, a detailed analysis on the frequency of each type of English and Malay cohesion found in English and Malay essays which takes into account students' proficiency levels was executed. The findings were presented in the form of bar graphs. 


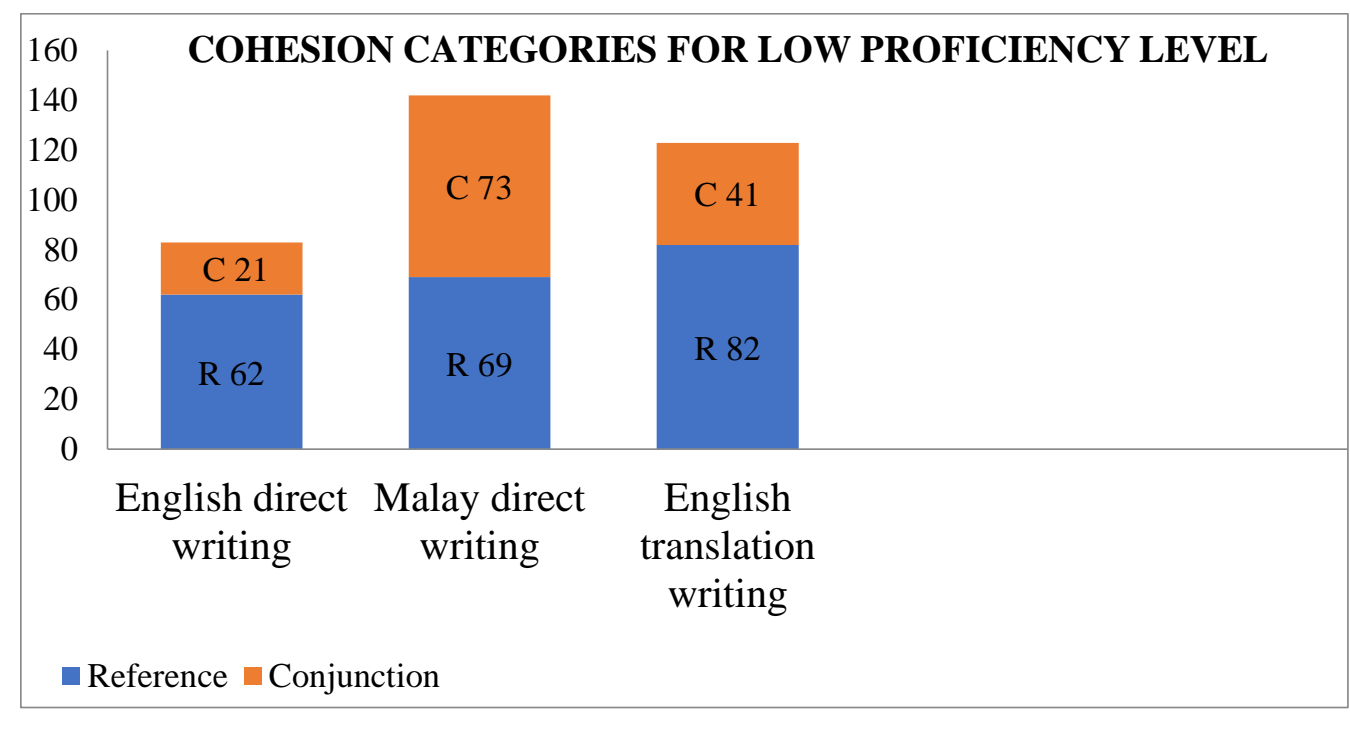

$$
\mathrm{R}=\text { Reference } \quad \mathrm{C}=\text { Conjunction } \quad \text { Bar Graph } 1
$$

The bar graph shows cohesion categories used by the low proficiency participants in general. The participants tend to use more reference cohesion as compared to conjunction cohesion in English direct writing as well as English translation writing. In Malay direct writing, however, the frequency of conjunction (73) outnumbered the reference (69) category.

Regarding the reference category, participants used more references (82) in English translation writing. As for the conjunction category, more conjunction (73) was used in Malay direct writing.

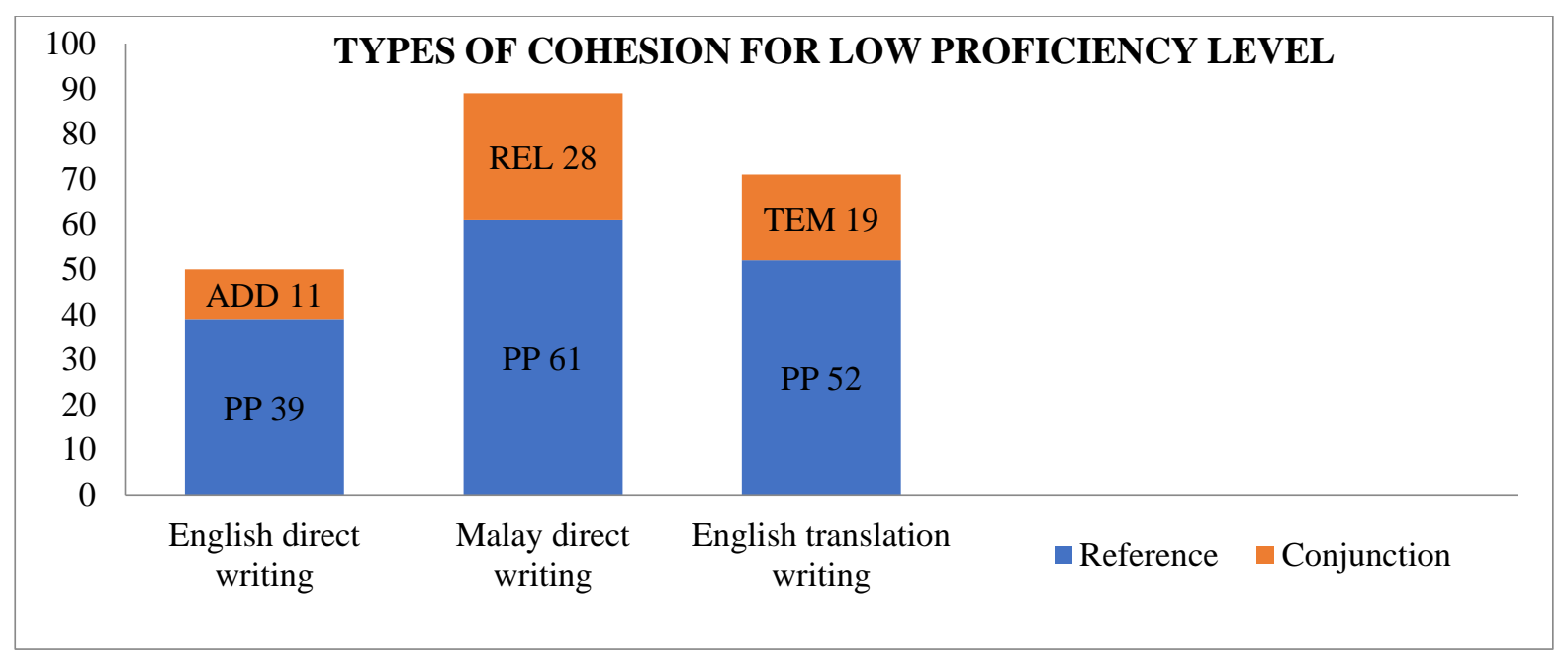

Reference $(\mathrm{PP}=$ Personal pronoun) Conjunction $(\mathrm{ADD}=$ Additive, $\mathrm{REL}=$ Relatif, $\mathrm{TEM}=$ Temporal)

Bar Graph 2

The bar graph presents the frequency of types of cohesion used by the low proficiency participants in specific. As for the reference category, the participants were likely to use a type of cohesion: personal pronoun (first person) in three writing processes. The bar graph indicates a more personal pronoun (61) written in Malay direct writing. As for the conjunction category, the participants favoured using a type of Malay cohesion: relative (yang), 28, written in Malay direct writing, followed by temporal (after, before), 19 in English translation and additive (and), 11 in English direct writing.

\subsection{Low proficiency level students}

Based on the findings above, low proficiency level students had a higher tendency in using reference cohesion category particularly the type of personal pronoun. This specific type, however, was found the highest in Malay direct writing as well as in English translation writing. It can be implied that these students were unable to generate more $\mathrm{L} 2$ personal pronouns in English direct 
writing due to a lack of the writing contents. In fact, if they managed to employ this specific type, they were likely to start their initial composition with first-person pronouns for instances; 'I and we' rather than the third personal pronoun singular for instances; 'she' and 'he' in order to avoid errors.

In relation to the conjunction cohesion category, low proficiency students used more of this category in Malay essays as compared to English essays only to signify that they managed to bring better elaboration of the contents in their native language. The outcome of the study was in tandem with previous studies done by Petchprasert (2013) on low intermediate Thai graduates.

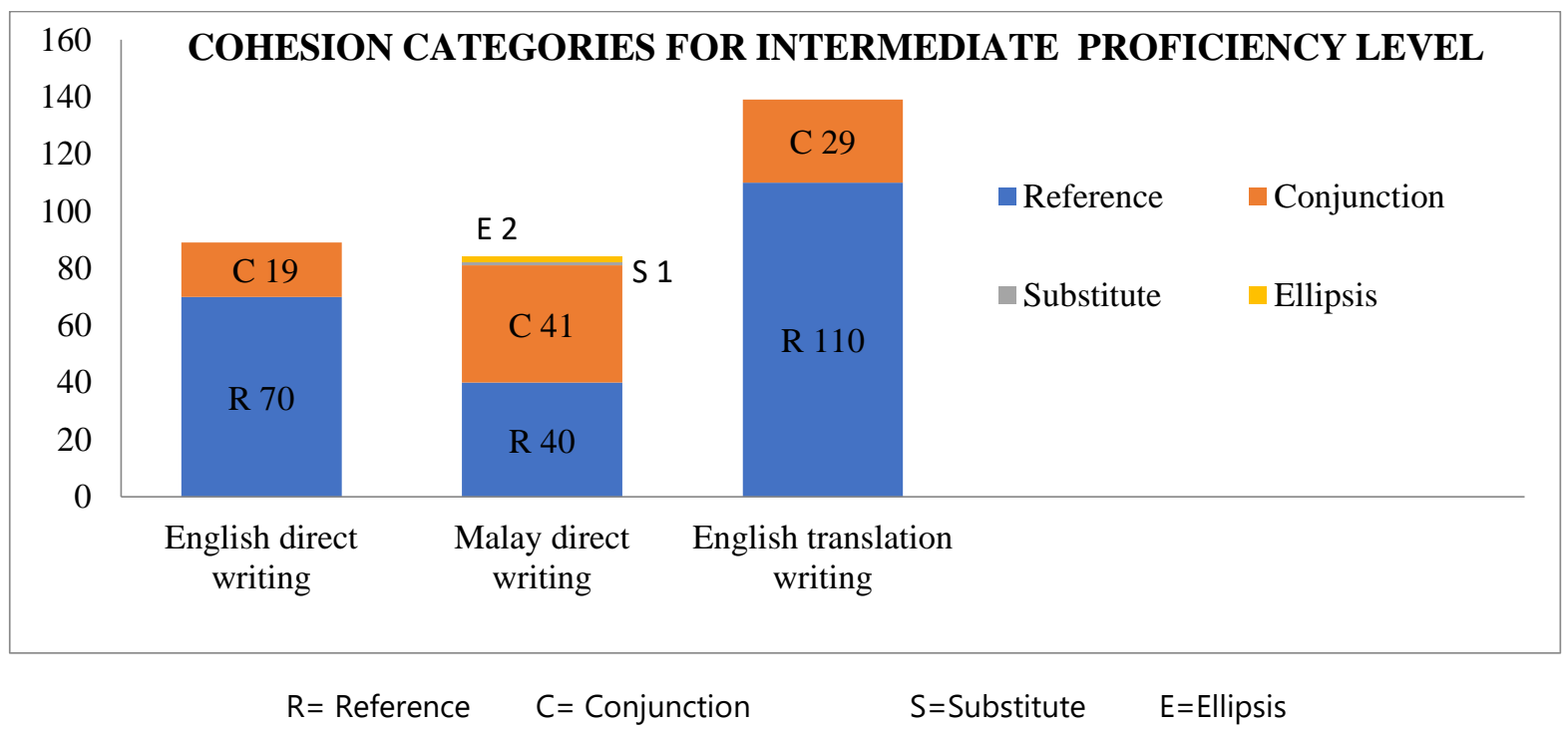

Bar Graph 3

The bar graph depicts cohesion categories used by the intermediate proficiency participants in general. Unlike the previous graph, another two new cohesion categories were found in this graph namely substitute and ellipsis. In relation to reference cohesion, participants were prone to use this cohesion category in English direct writing and English translation as compared to conjunction. Despite this, the conjunction outnumbered the reference with one insignificant difference in Malay direct writing.

Sharing the similar results in the previous graph, reference was found as the highest frequency (110) cohesion used in English translation writing; meanwhile, the conjunction was revealed as the highest frequency (41) cohesion written by the participants in Malay direct writing. Interestingly, ellipsis (2) and substitute (1) were found in Malay direct writing only.

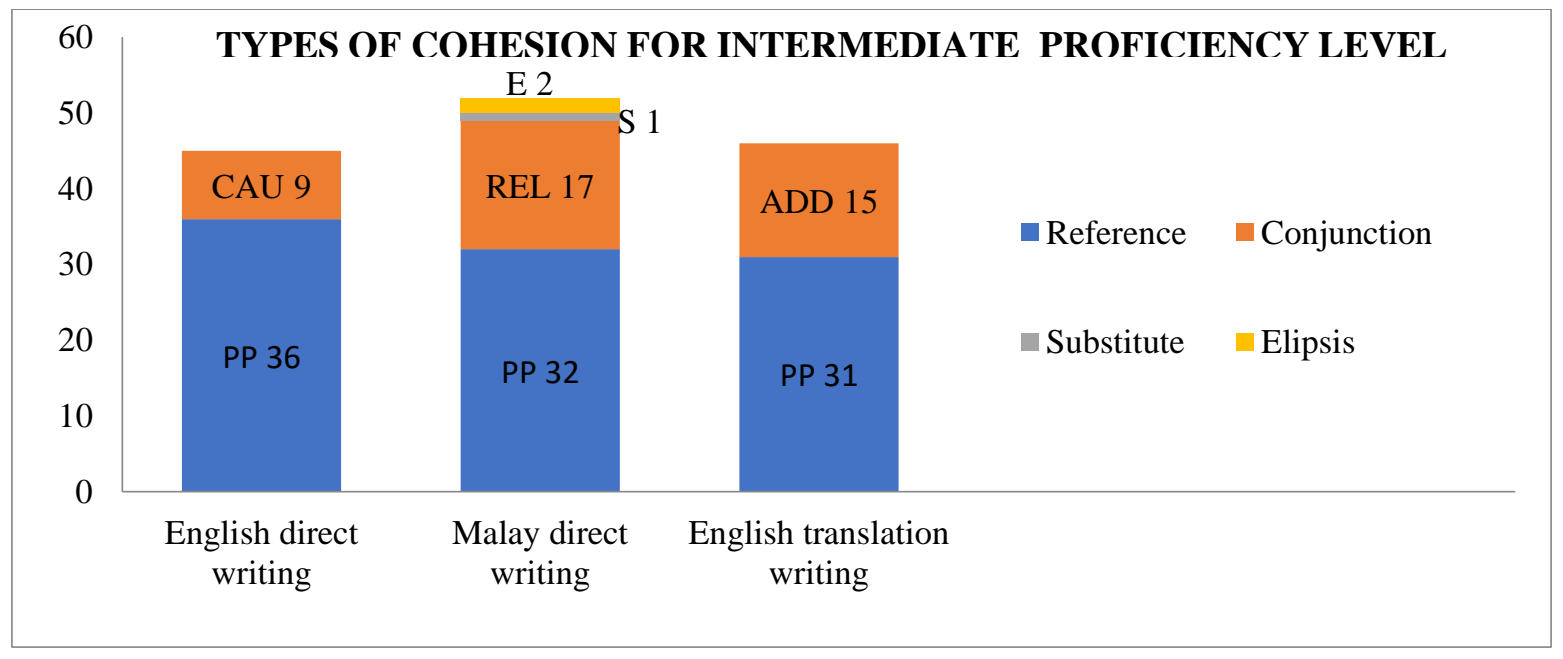

Reference (PP = Personal pronoun) Conjunction ( $\mathrm{ADD}=$ Additive,

REL= Relatif, $C A U=$ Causal) $S=$ Substitute $\quad E=$ Ellipsis

Bar Graph 4 
The bar graph denotes the frequency of types of cohesion used by the intermediate proficiency participants in specific. As for the reference category, the participants were likely to use a type of cohesion: personal pronoun (first person) in three writing processes. The bar graph shows more personal pronouns (36) written in English direct writing. As for the conjunction category, the participants preferred to use a type of Malay cohesion: relative (yang), 17, written in Malay direct writing, followed by additive (and), 15 in English translation, and causal (so, because), 9 in English direct writing. The least types of cohesion used were ellipsis (2) and substitute (1) in Malay direct writing.

\subsection{Intermediate proficiency level students}

As for intermediate proficiency students, this was considered as the second time when the personal pronoun cohesive type under the reference category was surprisingly lifted up as the highest frequency used by the students in English essays. As compared to the previous graph concerning low proficiency students, this outcome was totally tailored with intermediate proficiency students as they were expected to perform better than the low ones. Be that as it may, the intermediate students did not manage to display a wider significant difference.

Although intermediate proficiency students succeeded in portraying other categories of cohesion such as ellipsis and substitution, both categories, however, were seen in a Malay essay, not in English essays. It can be indicated that these students were categorised as less skilled and unable to produce more various types of English cohesions in English essays.

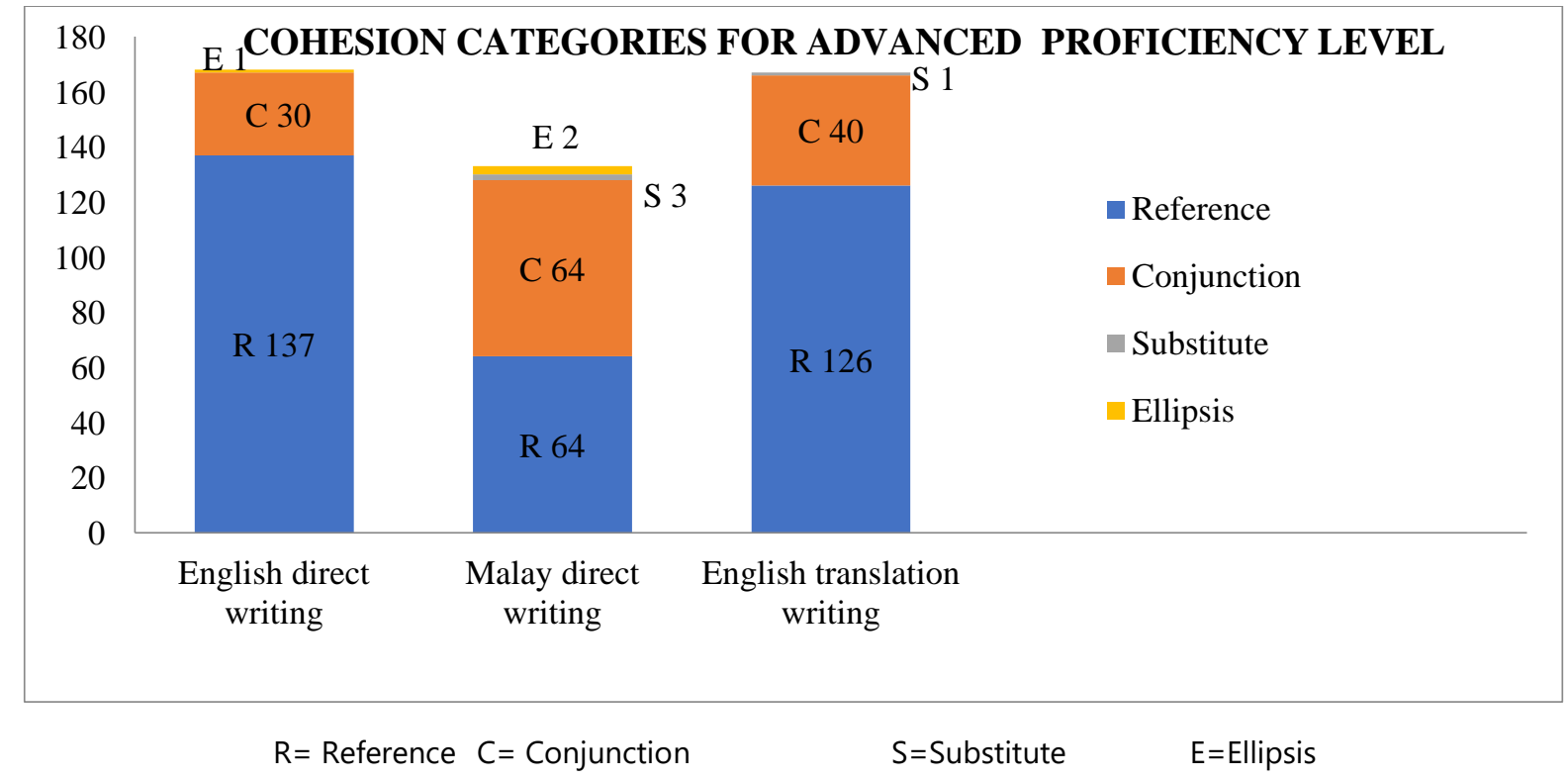

Bar Graph 5

The bar graph portrays cohesion categories used by the advanced proficiency participants in general. The reference cohesion was considered as the highest frequency used by participants as compared to conjunction in English direct writing as well as in English translation. Nevertheless, both reference and conjunction shared similar frequency (64) used in Malay direct writing by the participants.

Surprisingly, the advanced proficiency participants showed the highest tendency using the reference cohesion (137) in English direct writing compared to other writing processes whereas, more conjunction cohesion (64) were employed in Malay direct writing. If compared to the previous graphs (low and intermediate proficiency levels), the substitute cohesion was found in Malay direct writing (3) and English translation writing (1) and the ellipsis was used in English direct writing (1) as well as in Malay direct writing (2). 


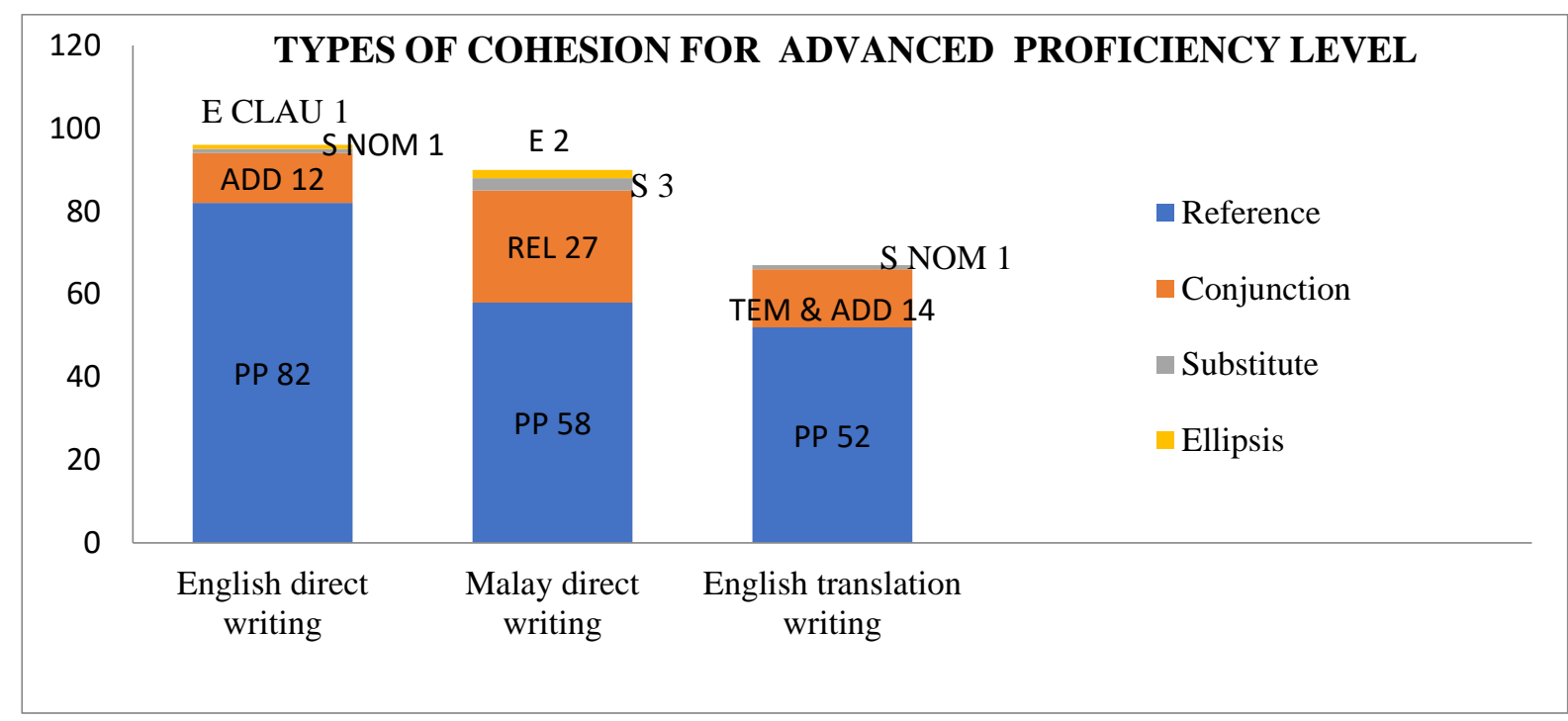

$$
\begin{gathered}
\text { Reference }(\mathrm{PP}=\text { Personal pronoun }) \quad \begin{array}{c}
\text { Conjunction }(\mathrm{ADD}=\text { Additive, } \\
\mathrm{REL}=\text { Relatif, } \mathrm{CAU}=\text { Causal, } \mathrm{TEM}=\text { Temporal }) \quad \mathrm{S}=\text { Substitute }(\mathrm{NOM}=\text { Nominal }) \\
\mathrm{E}=\text { Ellipsis }(\mathrm{CLAU}=\mathrm{CLAUSAL})
\end{array}
\end{gathered}
$$

Bar Graph 6

The bar graph indicates the frequency of types of cohesion used by the advanced proficiency participants in specific. As for the reference category, the participants tended to use a type of cohesion: personal pronoun (first person) in three writing processes. The bar graph displays that more personal pronoun (82) written in English direct writing. As for conjunction category, the participants preferred to use type of Malay cohesion: relative (yang), 27, written in Malay direct writing, followed by temporal (before, after), 14 and additive (and), 14 in English translation and another additive (and), 12 in English direct writing. The least types of cohesion used were substitute and ellipsis whereby the participants employed the substitute (3) in Malay direct writing, each substitute nominal (1) in English direct writing and English translation as well, whilst 2 ellipsis cohesions were written in Malay direct writing and 1 ellipsis clausal used in English direct writing.

\subsection{Advanced proficiency level students}

As for the advanced proficiency students, the cohesive type of reference category (personal pronoun) was illustrated as the highest frequency in English essays and the lowest one in Malay essays. Unlike the low proficiency students, the advanced students managed to produce more writing content in English essays. This led them to use the reference category, specifically, the cohesive type of personal pronoun as the narrative writing topics demanded them to use more expression and description of someone (related to the first topic) and something (related to the second topic). Nevertheless, this was not supposed to hinder the advanced students to creatively generate more variation in their sentence structure. This circumstance could be due to the advanced students' writing quality, as uncovered in the first research question was not picturing the real advanced proficiency level. Despite that, advanced students successfully produced ellipsis clausal and substituted nominal in English essays signifying better English competency as compared to low and intermediate students in previous graphs.

\section{Conclusion}

Generally, in exploring the impact of different writing modes, it is discovered that the writing processes, direct writing and translation writing together with participants' level of proficiency are the major factors influencing the quality of writing. Taking everything into account, the lower and intermediate level of proficiency learners benefitted the most. However, there should be specific guidelines on the degree of L1 use in L2 classrooms, particularly in developing writing skills. The present study focuses on the use of cohesive devices to analyse ESL learners' quality of writing.

On the whole, the frequency of the reference cohesion category specifically in personal pronoun as well as the cohesive types of additive (the use of 'and') and relative (the use of 'yang' for Malay cohesion) under conjunction outnumbered the other cohesion categories. All low, intermediate and advanced students favoured using both reference and conjunction in their writing in an attempt to describe, explain and connect the ideas to the rest of the written essays. Even though all the students relatively portrayed their language abilities according to their allotted proficiency levels (low, intermediate and advanced), yet the researchers perceived 
the outcomes of advanced level students were unable to shine more crucial and significant differences as if the advanced and intermediate students fairly shared similar English competency. This can be seen when overall English essays of direct writing showed less variety of cohesive markers as compared to Malay essays. This resulted in the lack of L2 writing skills among students and they apparently generated more ideas in their native language as well as utilised their L1 cohesive markers into L2 composition via the translation writing process.

Since this study purposely focused on a small sample size within a particular setting, it did not completely contribute to generalizing the overall use of direct writing and translation. It is suggested that future research could be done encompassing a wider range of samples in order to grasp the process of direct writing and translation in a Malaysian ESL context. Besides, a thorough process of writing can be gained by considering the students' own experience and opinions whereby methods like reading out aloud can be implemented in upcoming studies.

\section{References}

[1] Abbas, J. M., Yassim, M. S. M., \& Ismail, K. (2020). Arabic language influence on the Iraqi EFL tertiary learners' use of grammatical cohesive devices in their argumentative essays. European Journal of Social Sciences, 3(1), 56-64.

[2] Ahmed Ismail, S.A. \& Omer Alsheikh, N. (2012). Second language learners' performance and strategies when writing direct and translated essays. International Education Studies, 5(5), 173-184.

[3] Ali, H. M. M. (1996). Grammatical cohesion in Bahasa Melayu. International Islamic University.

[4] Asmah, O. (1986). Bahasa dan Pemikiran Alam Melayu. Dewan Bahasa dan Pustaka.

[5] Creswell, J.W. (2014). Educational research: Planning, conducting and Evaluating quantitative and qualitative research (4 ${ }^{\text {th }}$ ed.). Pearson Education Limited

[6] Cumming, A. (189). Writing expertise and second language proficiency. Language Learning, 39, 81-141.

[7] Eckman, F. (1977). Markedness and the contrastive analysis hypothesis. Language Learning, 27, 315-330.

[8] Witte, S. \& Faigley, L. (1981). Analysing revision. College Composition and Communication. 32 (4), 400-414

[9] Gass, S.M. (2000). Fundamental of second language acquisition. In J.W. Rosenthal (Ed.), Handbook of undergraduate second language education (p. 29-46). Mahwah, New Jersey: Lawrence Erlbaum Associate, Inc., Publishers.

[10] Halliday, M. A. K. \& Hasan, R. (1976). Cohesion in English. Longman.

[11] Karim, K. \& Nassaji, H. (2013). First language transfer in second language writing: An examination of current research. Iranian Journal of Language Teaching Research, 1(1), 117-134.

[12] Kim, Y. \& Yoon, Hyunsook. (2014). The use of L1 as a writing strategy in L2 writing tasks, Journal of Language, 14(3), 33-50.

[13] Kobayashi, H., \& Rinnert, C. (1992). Effects of First Language on Second Language Writing Translation Versus Direct Composition. Language learning, 42(2), 183-209

[14] Liaw, Y. F. \& Abdullah, H. (1994). Nahu Melayu Moden. Fajar Bakti.

[15] Lifang, Z. (2008). Comparison of two writing processes: Direct versus translated composition. Cross-cultural Communication, 4(1), 8-17.

[16] Myles, J. (2002). Second language writing and research: The writing process and Error analysis in student texts. Retrieved December 20, 2015, from http://tesl-ej.org/ej22/a1.html

[17] Nik Safiah, K., Farid M. O., Hashim, M., \& Abdul Hamid, M. (1993). Tatabahasa Dewan. Dewan Bahasa dan Pustaka.

[18] Petchprasert, A. (2013). A study of cohesive markers used in L1 and L2 essay writing: Translation versus direct composition. The Southeast Asian Journal of English Language Studies, 19(1), 19-33.

[19] Rassouli, M. \& Abbasvandi, M. (2013). The effects of explicit instruction of grammatical cohesive devices on intermediate Iranian learners' writing. European Online Journal of Natural and Social Sciences, 2 (2), 15-22.

[20] Selinker, L. (1983). Language transfer. Language Transfer in Language Learning. Newbury House

[21] Silva, T. (1993) towards an understanding of the distinct nature of L2 writing: The ESL research and its implication. TESOL Quarterly, 27, 657677.

[22] Stapa, S. H., \& Majid, A. H. A. (2006). The use of first language in limited English proficiency classes: Good, bad or ugly? Retrieved December 20, 2015 from http://pkukmweb.ukm.my/e-bangi/papers/2006/sitihami.pdf

[23] Tangkiengsirisin, S. (2010). Promoting cohesion in EFL expository writing: A study of graduate students in Thailand. International Journal of Arts and Sciences, 3(16), 1-34.

[24] Van Weijen, D., Van Den Bergh, H., Rajlaarsdam, G., \& Sanders, T. (2009). L1 use in L2 writing: An Empirical study of a complex phenomenon. Journal of Second Language Writing, 18, 235-250. 